Supplement of Biogeosciences, 18, 2843-2857, 2021 https://doi.org/10.5194/bg-18-2843-2021-supplement (c) Author(s) 2021. CC BY 4.0 License.

(c) (1)

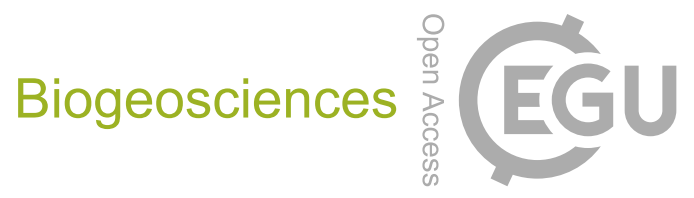

Supplement of

\title{
Sun-induced fluorescence and near-infrared reflectance of vegetation track the seasonal dynamics of gross primary production over Africa
}

Anteneh Getachew Mengistu et al.

Correspondence to: Anteneh Getachew Mengistu (antenehgetachew7@gmail.com)

The copyright of individual parts of the supplement might differ from the article licence. 
Table S1. Linear regression results for NIRv and SIF with MPI-BGC GPP from over major biomes of Africa temporally averaged for the years $(2007$ - 2011). $y$ is the GPP inferred from NIRv/SIF and $\mathrm{x}$ is the NIRv/SIF signal. $\mathrm{R}$ is the spatial correlation coefficient between these signals and MPI-BGC GPP.

\begin{tabular}{cccccc}
\hline Biome & \multicolumn{2}{c}{ MPI-BGC GPP $\left(\frac{K g C}{m^{2} y r}\right) \&$ NIRv } & \multicolumn{2}{c}{ MPI-BGC GPP \& SIF $\left(\frac{n W}{s r m^{2} n m}\right)$} & Number of data points \\
& fitting equation & $\mathrm{R}^{2}$ & fitting equation & $\mathrm{R}^{2}$ & \\
\hline $\begin{array}{c}\text { Broad leaf } \\
\text { evergreen Forest } \\
\text { C3 grass }\end{array}$ & $\mathrm{y}=9.06 * \mathrm{x}+0.51$ & 0.38 & $\mathrm{y}=1.07 * \mathrm{x}+1.58$ & 0.16 & 574 \\
$\begin{array}{c}\text { Shrub Northern } \\
\text { Africa }\end{array}$ & $\mathrm{y}=10.33^{*} \mathrm{x}-0.24$ & 0.86 & $\mathrm{y}=1.92 * \mathrm{x}+0.10$ & 0.77 & 480 \\
$\begin{array}{c}\text { Shrub Southern } \\
\text { Africa }\end{array}$ & $\mathrm{y}=13.55^{*} \mathrm{x}-0.62$ & 0.96 & $\mathrm{y}=2.51 * \mathrm{x}-0.10$ & 0.83 & 325 \\
$\begin{array}{c}\text { C4 grass } \\
\text { Northern Africa } \\
\text { C4 grass }\end{array}$ & $\mathrm{y}=12.54 * \mathrm{x}-0.73$ & 0.88 & $\mathrm{y}=2.23 * \mathrm{x}-0.54$ & 0.86 & 1382 \\
Southern Africa & $\mathrm{y}=13.79 * \mathrm{x}-0.75$ & 0.85 & $\mathrm{y}=2.55 * \mathrm{x}-0.38$ & 0.83 & 1108 \\
\hline
\end{tabular}

Table S2. comparison of biome specific estimates of five years mean GPP covering the period from 2007 to 2011 for major biomes of Africa as derived from: leaner regression of SIF/NIRv-vs-EC-GPP and Max-Planck Ensemble GPP (MPI-GPP).

\begin{tabular}{|l|l|l|l|l|l|l|}
\hline Leave type & BLEF & Shrub NH & Shrub SH & C3 grass & C4 grass NH & C4 grass SH \\
\hline SIF-GPP $\left(\mathrm{Kg} \mathrm{Cm}^{-2} \mathrm{yr}^{-1}\right)$ & 2.52 & 1.34 & 0.90 & 1.15 & 1.04 & 0.82 \\
\hline NIRv-GPP $\left(\mathrm{Kg} \mathrm{Cm}^{-2} \mathrm{yr}^{-1}\right)$ & 2.53 & 1.81 & 0.3 & 1.18 & 1.33 & 1.26 \\
\hline MPI-GPP $\left(\mathrm{Kg} \mathrm{Cm}^{-2} \mathrm{yr}^{-1}\right)$ & 2.44 & 1.24 & 1.19 & 1.10 & 1.01 & 1.15 \\
\hline
\end{tabular}



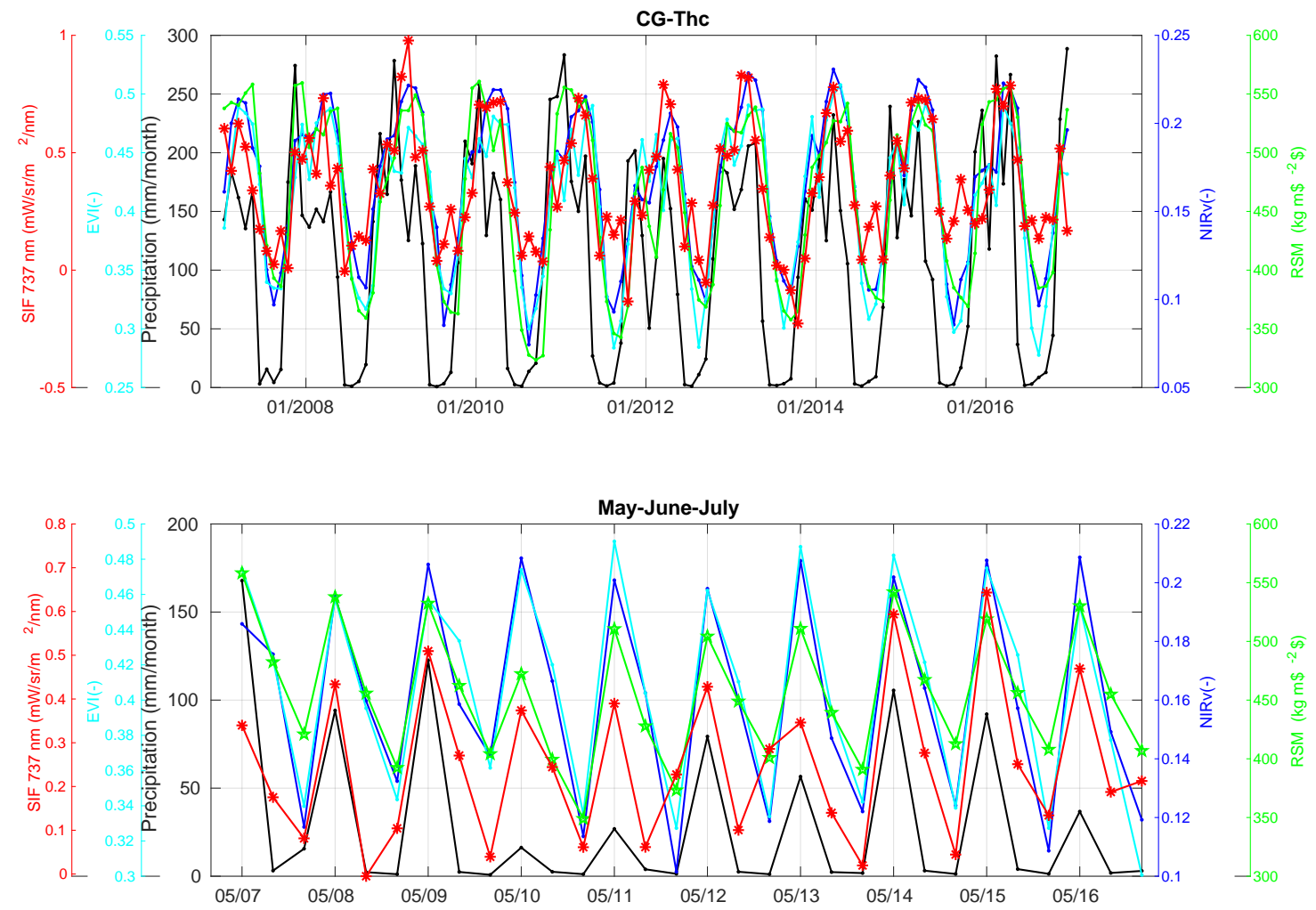

Figure S1. Time series of SIF, NIRv Precipitation and soil moisture.. 

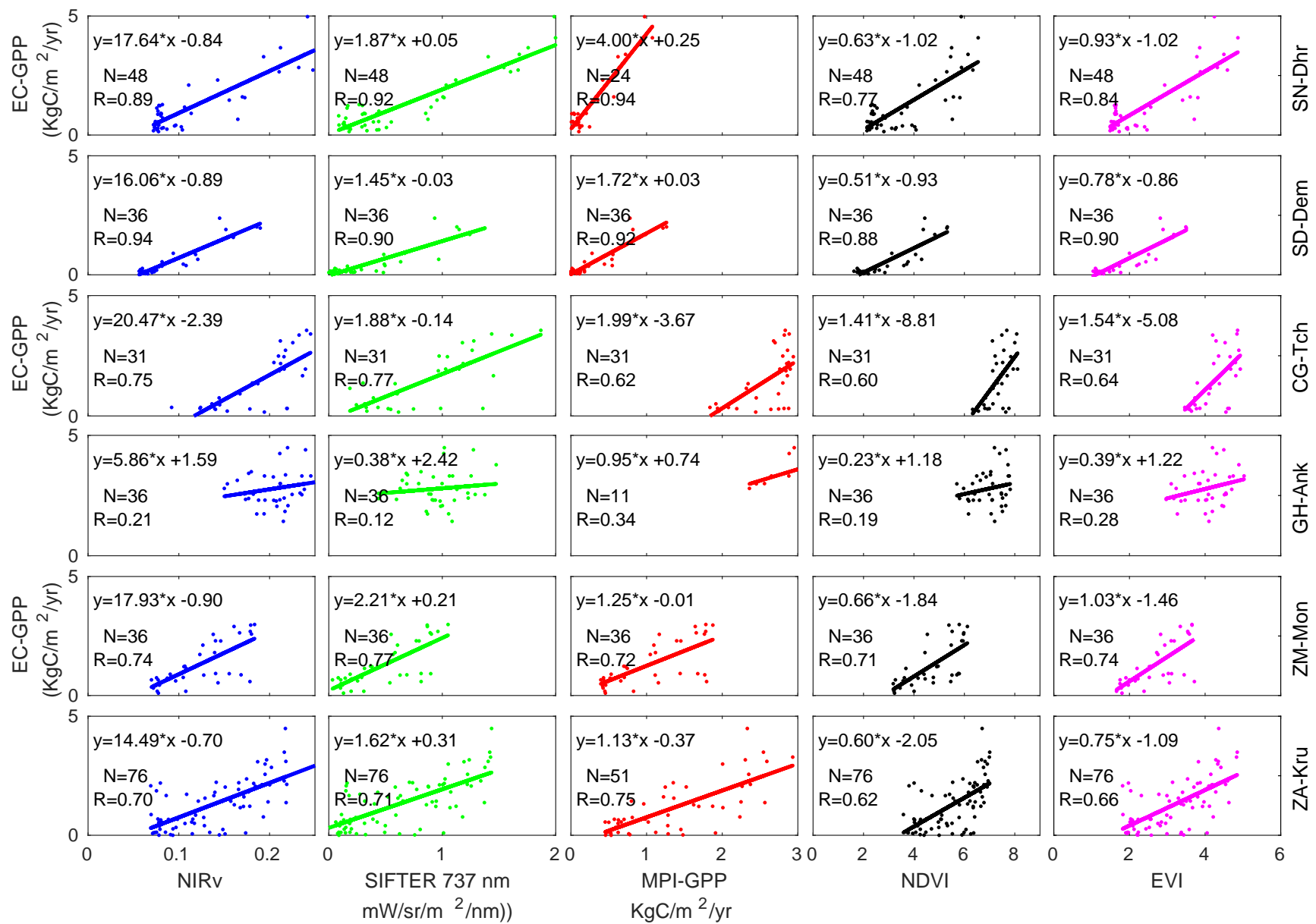

Figure S2. Comparison of eddy covariance GPP with NIRv, SIF, MPI-BGC GPP, NDVI and EVI for major biomes around the flux-tower. To obtain sufficient data the comparison is made by averaging monthly values within a $4^{\circ} \times 4^{\circ}$ window enclosing the tower. Furthermore, to account for vegetation heterogeneity of the land, grid cells with a different vegetation type than for the tower location were masked. 

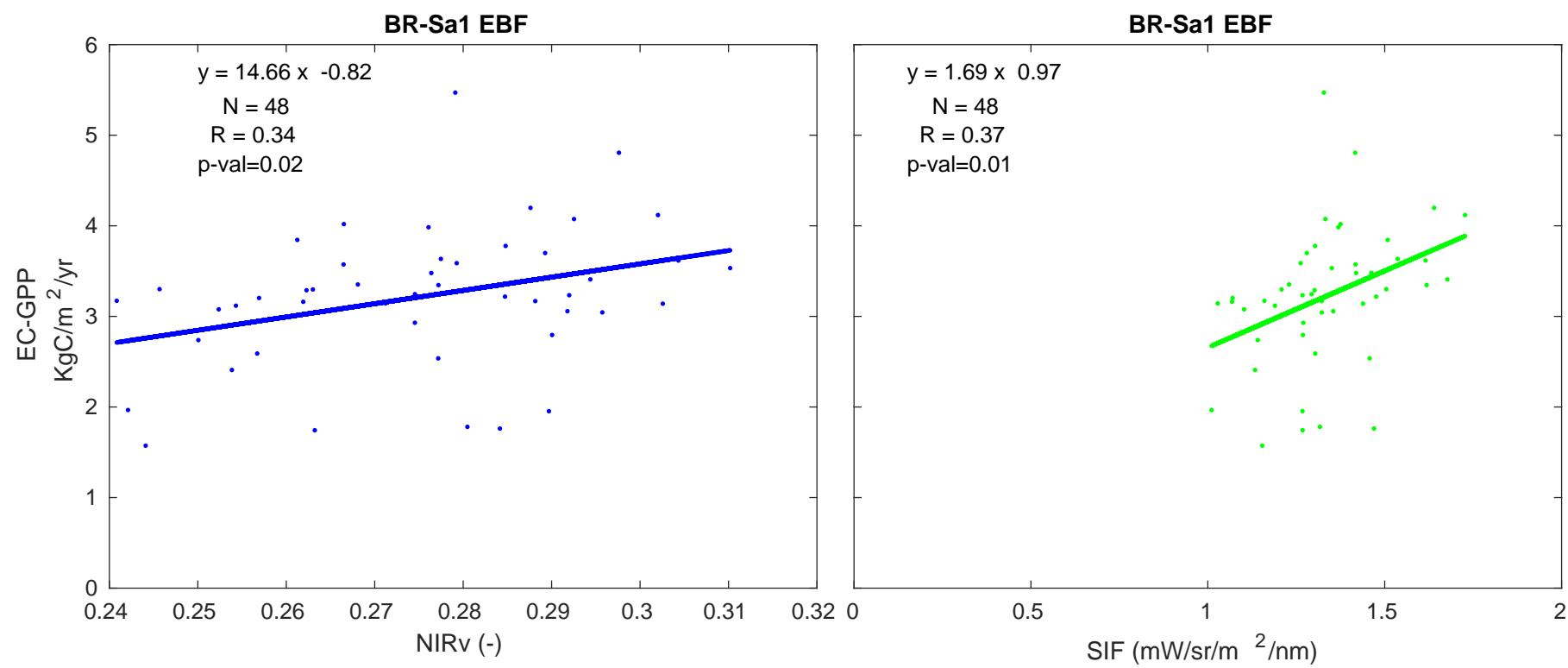

Figure S3. Comparison of eddy covariance GPP with NIRv and SIF around the Brazil BR-Sa1 flux tower. To obtain sufficient data the comparison is made by averaging monthly values within a $4^{\circ} \times 4^{\circ}$ window enclosing the tower. Furthermore, to account for vegetation heterogeneity of the land, grid cells with a different vegetation type than for the tower location (evergreen broad-leaf forest) were masked. The regression slope and intercepts are used to infer GPP from NIRv and SIF over African broad-leaf evergreen forest. 
a)

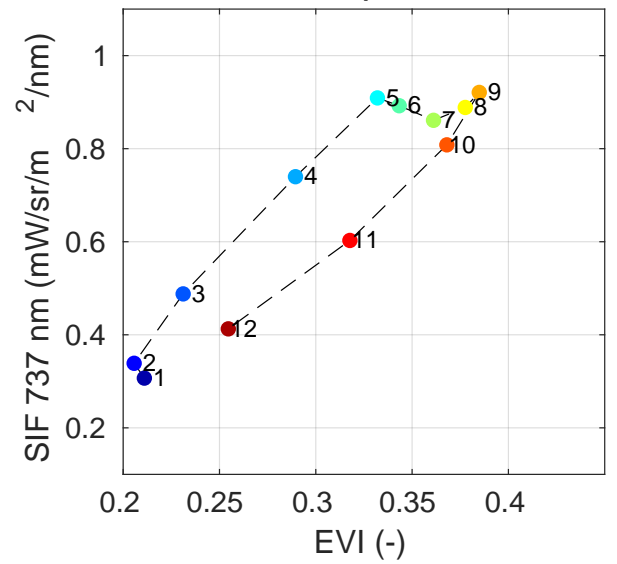

b)

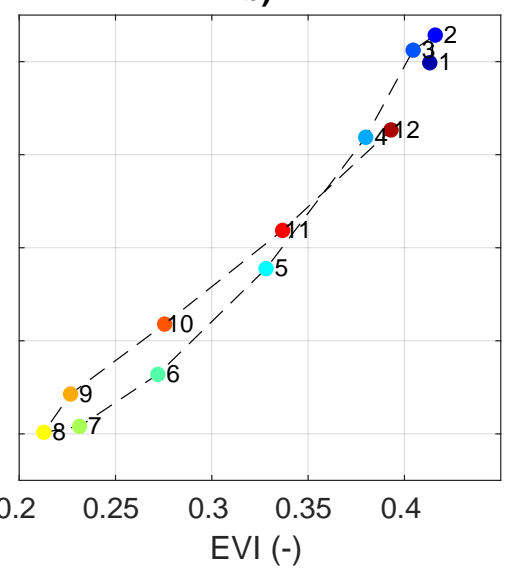

Figure S4. Seasonal values SIF verses EVI as a response of C3 grass and shrub vegetation types of Africa a) Northern of the equator and b) South of the equator. 
a)

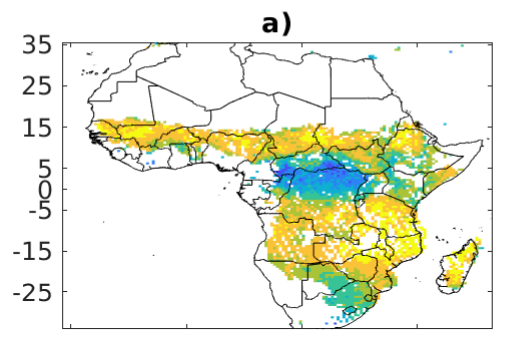

c)

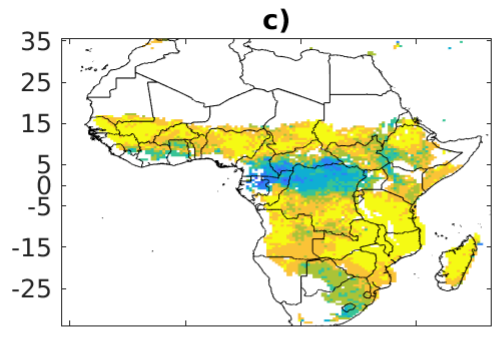

e)

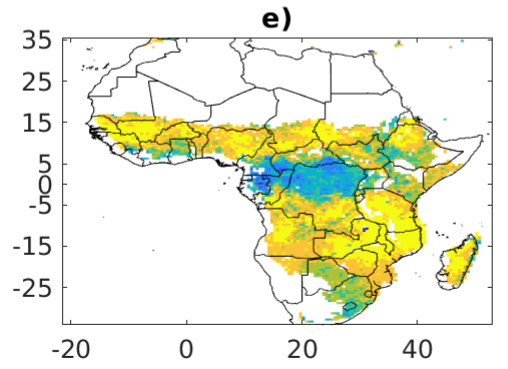

b)

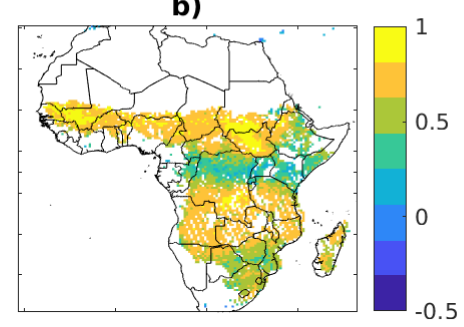

d)

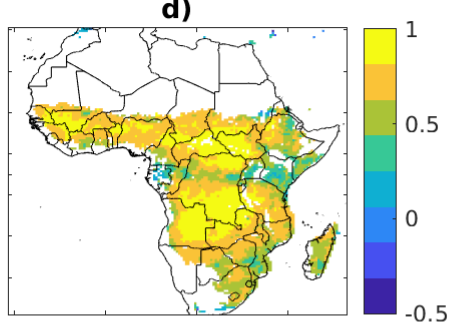

f)

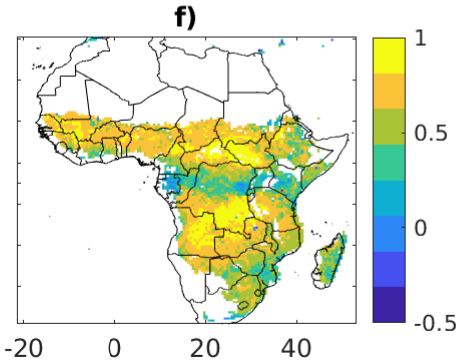

Figure S5. correlation of SIF a) NIRv c) and EVI e) with root zone soil moisture from GLDAS, and SIF b), NIRv d) and EVI f) with precipitation from GPCC for the years 2007-2016. 